\title{
Experimental Investigation of Ternary Al-Si-Cu Alloy Solidified with Unsteady-State Heat Flow Conditions
}

\author{
Luis Antônio de Souza Baptista ${ }^{a}$, Alexandre Furtado Ferreira ${ }^{a, b} *$, Késsia Gomes Paradela ${ }^{a}$, \\ Dimas Moraes da Silva ${ }^{a}$ José Adilson de Castro ${ }^{a, b}$ \\ aPrograma de Pós-Graduação em Engenharia Metalúrgica, Universidade Federal Fluminense, \\ 27255-125, Volta Redonda, RJ, Brasil. \\ ${ }^{b}$ Programa de Pós-Graduação em Engenharia Mecânica, Universidade Federal Fluminense, \\ 27255-125, Volta Redonda, RJ, Brasil.
}

Received: June 07, 2017; Revised: January 03, 2018; Accepted: February 07, 2018

\begin{abstract}
Ternary Al-9.0wt $\% \mathrm{Si}-4.0 \mathrm{wt} \% \mathrm{Cu}$ alloy was solidified in a vertical directional solidification system under unsteady-state heat flow conditions. The resulting dendritic morphology and microsegregation were investigated. A more detailed analysis was dedicated to the microsegregation phenomena where a multielement interaction was observed. The solidification parameters such as: solidification speed $\left(\boldsymbol{V}_{L}\right)$ and cooling rate $(\dot{\boldsymbol{T}})$ were determined from the cooling curves obtained during the solidification process. The thermal variables effect on the dendritic morphology is presented. The measurements of tertiary dendrite arm spacing $\left(\lambda_{3}\right)$ and microsegregation were performed for different positions along the casting. The experimental curves for microsegregation were obtained for $\mathrm{Si}$ and $\mathrm{Cu}$ from the center of dendritic tertiary arm to the next nearest tertiary arm. The solidification speed $\left(\boldsymbol{V}_{L}\right)$ influence is "built into" the effective partition coefficient $\left(\boldsymbol{K}_{e f_{-} \mathrm{Cu}}\right.$ and $\left.\boldsymbol{K}_{\text {ef } S i}\right)$ that has been determined for the range of $\boldsymbol{V}_{L}$ and microsegregation curves are calculated by Scheil's equation for comparison with experimental data. Good agreements of the Scheil's equation with experimental data on microsegregation curves of the Si and Cuwere obtained when effective partition coefficient $\left(\boldsymbol{K}_{e f_{C u}}\right.$ and $\left.\boldsymbol{K}_{e f S i}\right)$ is taken into consideration. The multielement interaction effect on the Si microsegregation is investigated. Experimental results show that, $\mathrm{Cu}$-rich dendrites were accompanied by minute amounts of $\mathrm{Si}$. The concentration profiles obtained experimentally point to a strong negative correlation between $\mathrm{Si}$ and $\mathrm{V}_{\mathrm{L}}$ on ternary Al-9.0wt $\% \mathrm{Si}-4.0 \mathrm{wt} \% \mathrm{Cu}$ alloy.
\end{abstract}

Keywords: Ternary Al-Si-Cu alloy, tertiary dendrite arm spacing, microsegregation, directional solidification.

\section{Introduction}

During casting process of alloys a large variety of microstructures can be observed. The most commonly found ones are known as cell, dendrite and eutectic morphology. The formation of dendrites is a common mechanism of crystallization from high solidification speeds in the metals and alloys. A convenient and widely used technique to investigate the effects of solidification conditions on the resulting microstructures is based on the measurements of dendritic spacing, which is the distance between the dendritic primary, secondary or higher orders arms. On the other hand, dendritic arm spacing has strong influence on both microsegregation patterns and second phase formation in the interdendritic regions during solidification process. The formation of dendritic morphology during solidification and the microsegregation process have fascinated researchers for literally hundreds of years. The solidification thermal parameters have influence on the microstructure and microsegregation andthese, in turn, are key featuresin inducing non-uniformity on the as-cast material mechanical properties. For this reason, the microstructure and microsegregation has been extensively studied both theoretically ${ }^{1-11}$ and experimentally ${ }^{12-25}$ for the last decades. The Al-1.2wt $\% \mathrm{~Pb}$ and $\mathrm{Al}-3.2 \mathrm{wt} \% \mathrm{Bi}$ alloys have been chosen by Freitas et al. ${ }^{13}$, to study the effect of microstructural parameters on the wear process. The solidification experiments were achieve under non-stead state conditions of heat flow with a large amplitude of cooling rates, which allows a variation on the dendritic morphology. The results obtained by Freitas et al. ${ }^{13}$, show that interphase spacing and the morphology of the minority phase have a strong effect on the wear process. Spinelli et al. ${ }^{12}$ proposed a theoretical and experimental work to investigate the thermal parameters during solidification process of binary $\mathrm{Sn}-\mathrm{Pb}$ alloys. The results obtained by Spinelli et al. ${ }^{12}$ indicate that CET (columnar to equiaxed transition) occurrence may have 
been influenced by convection process. In that paper, in downward solidification conditions, the convection process seems to favor the CET occurrence. Growth direction has effect on the primary dendritic arm spacing, in other words, decreasing the dendritic arm spacing for downward vertical solidification when compared with those grown vertical upwards. Goulart et al. ${ }^{15}$ have investigated the resulting structure of solidification in hypoeutectic binary alloys (Al-Fe) with unsteady-state heat flow conditions, both solidification speed and cooling rate are quantitatively determined in that work. Goulart et al. ${ }^{15}$ found that cellular microstructures are predominant in the entire castings for alloys investigated. Furthermore, cellular spacing as function of both solidification speed and cooling rate, it is not affected by concentration of iron solute, and metal/mold heat transfer coefficient can be determined via a power function of time. Meza et al. ${ }^{16}$ have executed experiments of unidirectional solidification in aluminum-based systems (Al-Cu and Al-Fe). Composition from dendritic cores to interdendritic regions was numerically determined by Meza et al. ${ }^{16}$. The authors have adopted an experimental equation for solute concentration $(\mathrm{Cu}$ and $\mathrm{Fe})$ which shows a good agreement to the experimental data. They have shown that solidification speed has significant effect on the resulting microsegregation curves. Several works ${ }^{1-5,12-18}$ have been carried out which highlighted the importance of taking into account the thermal parameters effect on the microstructure and microsegregation during solidification process. Several experimental researches have been proposed for binary alloys of metallurgical interest. However, experimental works focused on the multicomponent alloys are still rare in the literature ${ }^{1,17}$. The present experimental paper is based on the research line of previous references, highlighting the correlation between the thermal parameters and tertiary dendrite arm spacing $\left(\lambda_{3}\right)$ and microsegregation during solidification of a ternary Al-9.0wt $\% \mathrm{Si}-4.0 \mathrm{wt} \% \mathrm{Cu}$ alloy under unsteady-state heat flow conditions. However, in the present work the numerical results for microsegregation are obtained by disregarding the equilibrium partition coefficient $\left(\boldsymbol{K}_{e q}\right)$ and, instead, adopting an effective partition coefficient $\left(\boldsymbol{K}_{e f}\right)$. The multielement interaction effect on the $\mathrm{Si}$ microsegregation in the ternary $\mathrm{Al}-9.0 \mathrm{wt} \% \mathrm{Si}-4.0 \mathrm{wt} \% \mathrm{Cu}$ alloy during solidification process is investigated. This approach constitutes the main innovative feature of the present work. A model for microsegregation analysis of the solidification process is referred as Scheil's equation ${ }^{18,26}$. The assumptions considered in Scheil's equation (1) are described as follows: a) no diffusion in solid phase; b) infinitely fast diffusion occurs in the liquid and; c) equilibrium exists at the solid/ liquid interface and so compositions from phase diagram can be considered.

$$
C_{S}=K_{e q} C_{0}\left(1-F_{s}\right)^{K_{e q}-1}
$$

where $C_{S}$ is the concentration in the solid region, $C_{0}$ the initial overall composition and $\boldsymbol{F}_{S}$ the solid fraction. Although the influence of solidification speed $\left(\boldsymbol{V}_{L}\right)$ and cooling rate $(\dot{\boldsymbol{T}})$ on the microstructural characteristics was the focus of many studies ${ }^{1-4,12-16}$, literature on the influence of these parameters on the microsegregation profiles are still quite limited ${ }^{21}$. Burton et al. ${ }^{9}$ proposed an equation for effective distribution coefficient $\left(\boldsymbol{K}_{e f}\right)$ as a function of the solidification speed $\left(\boldsymbol{V}_{L}\right)$. The equilibrium partition coefficient can be replaced by this effective distribution coefficient into the Scheil microsegregation model. Burton proposes the following equation for $\boldsymbol{K}_{e f}$

$$
K_{e f}=\frac{K_{e q}}{K_{e q}+\left(1-K_{e q}\right) e^{\left(\frac{V_{L} \delta}{D_{L}}\right)}}
$$

where $\boldsymbol{\delta}$ diffusion layer thickness of the segregated solute ahead the solid/liquid interface and $D_{L}$ is the liquid solute diffusivity. Physical properties adopted for this work were the same those used by Qiang et al. ${ }^{5}$ and Wesner et al. ${ }^{6}$ and are shown in Table 1.

Table 1. Physical properties ${ }^{21,22}$.

\begin{tabular}{lcc}
\hline Solute & $\boldsymbol{D}_{L}\left(\mathrm{~m}^{2} / \mathrm{s}\right)$ & $\boldsymbol{\delta}(\mathrm{m})$ \\
\hline $\mathrm{Cu}$ & $3.6 \times 10^{-9}$ & $1.0 \times 10^{-5}$ \\
\hline
\end{tabular}

The $\boldsymbol{\delta}$ depends on the solidification speed $\left(\boldsymbol{V}_{L}\right)$, the liquid viscosity and the agitation condition ahead the solid/ liquid interface, and its value can vary from $10^{-6}$ to $10^{-3} \mathrm{~m}$, according to the Chalmers cited by Meza et al. ${ }^{16}$.

\section{Experimental Procedure}

The experimental technique adopted was previously described in more details ${ }^{14-16}$. A ternary Al-9.0wt\% $\%$ Si$4.0 \mathrm{wt} \% \mathrm{Cu}$ alloy was prepared in a furnace to $800^{\circ} \mathrm{C}$, from the high-purity materials $(99.9 \% \mathrm{Al}, 99.7 \% \mathrm{Si}$ and $99.9 \% \mathrm{Cu})$. The chemical analysis of the ternary alloy has been checked via conventional spark emission spectroscopy. The melt was then cast into a steel mouldof a special apparatus in orderto obtain a vertical upward transient directional solidification. A thin steel plate is used to close the base of the steel mold, which separates the melt from water-cooling system.

Solidification apparatus details are shown in Figure 1. The pouring temperature $\left(\boldsymbol{T}_{P}\right)$ was setup at $55^{\circ} \mathrm{C}$ above its liquidus temperature $\left(\boldsymbol{T}_{L}\right)$. The surface of the cooling base of the mold was polished in order to allow a good contact with the melt and, therefore, a higher heat transfer process. This creates favorable conditions to obtain a higher range of cooling rates during the solidification process. The temperature data were measured by type $\mathrm{K}$ thermocouples. The thermocouples were positioned along of the casting $5,10,15,20,35,45,60$ and $85 \mathrm{~mm}$ from the mold bottom. 
The temperature data were sampled at $0.01 \mathrm{~s}$ intervals by a data logger interface and stored in a personal computer. An Olympus Optical Microscope (Olympus Corporation, Japan) was used to produce digital images that were analyzed using Goitaca (https://sourceforge.net/projects/goitacaeq) image processing software in order to measure the tertiary dendritic spacing $\left(\lambda_{3}\right)$. A scanning electron microscope JEOL (JEOL, Ltd., Japan) model JSM 5800LV with energy-dispersive spectrometer NORAN System 6, (Thermo Fisher Scientific), was used for the solutes concentration measurements. Although WDS could present a better detection limit than EDS, for the elements and composition range involved it has been considered that EDS would be cheaper and faster process. The concentration measurement initiates at the dendritic arm centre and ends at the centre of adjacent arm, as shown in Figure 2.

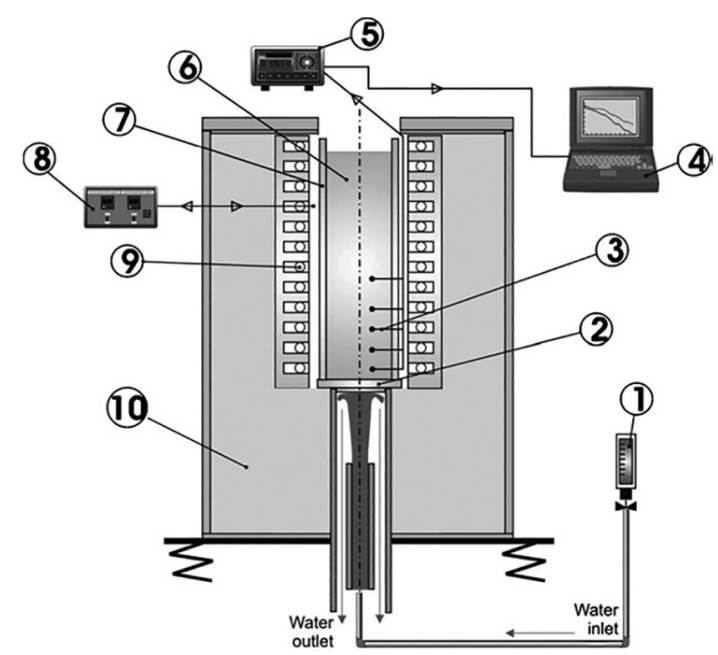

Figure 1. Diagrammatic representation of equipment: (1) rotameter; (2) thin steel plate; (3) thermocouples; (4) temperature acquirement software and computer; (5) data logger; (6) melt; (7) steel mold; (8) temperature controller; (9) electric heaters; (10) insulating ceramic shielding.

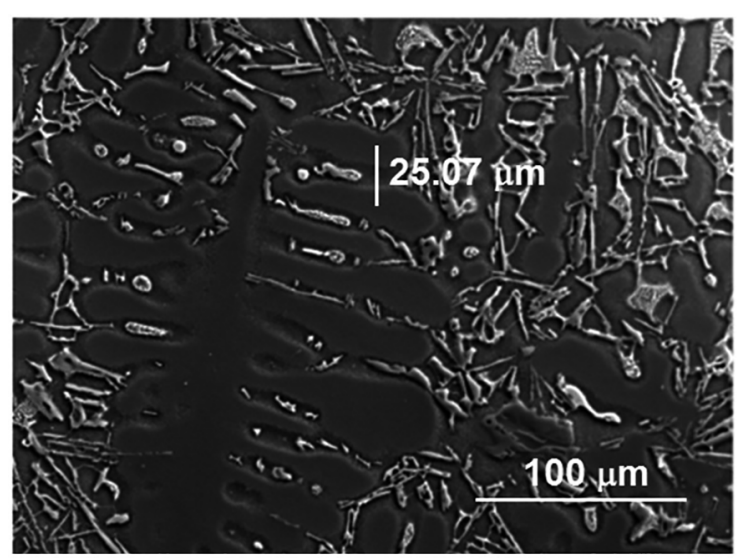

Figure 2. Track adopted for microsegregation profiles in dendritic arm of a ternary $\mathrm{Al}-9.0 \mathrm{wt} \% \mathrm{Si}-4.0 \mathrm{wt} \% \mathrm{Cu}$ alloy.
The concentration measurements were performed in samples taken from positions very close to the tip of the thermocouples. About 40 concentration measurements were performed for each position along the casting. The solidification speed for each position along the casting varied between $0.22-1.19 \mathrm{~mm} / \mathrm{s}$.

\section{Results and Discussion}

The cooling curves recorded by the thermocouples of the ternary $\mathrm{Al}-9.0 \mathrm{wt} \% \mathrm{Si}-4.0 \mathrm{wt} \% \mathrm{Cu}$ alloy, from the onset of solidification experiment, are shown in Figure 3. The temperatures measured by the thermocouples along the casting allow determining the position of liquidus temperature during solidification process. Figure 4 correlates the position of liquidus isotherm $(\boldsymbol{P})$ and solidification speed $\left(\boldsymbol{V}_{L}\right)$ with time during the solidification process for the ternary Al-9.0wt $\%$ Si-4.0wt $\% \mathrm{Cu}$ alloy.

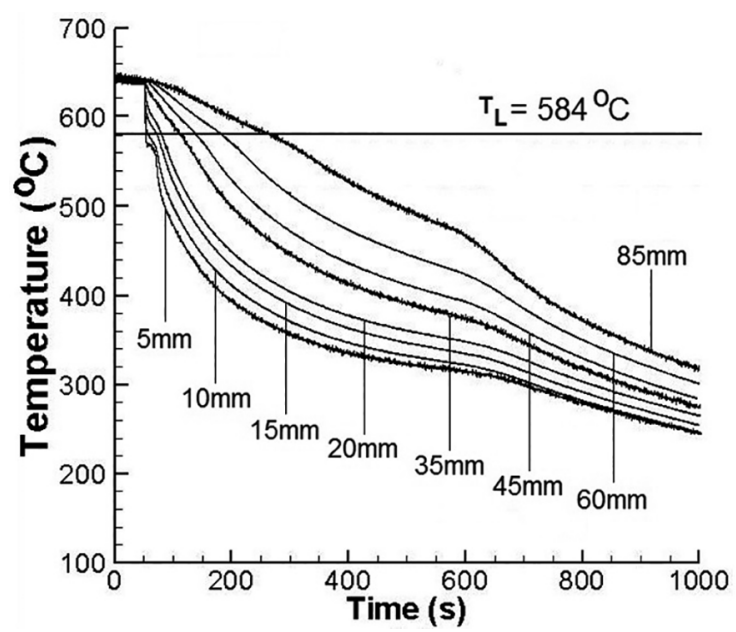

Figure 3. Experimental cooling curves for a ternary Al-9.0wt $\% \mathrm{Si}-$ $4.0 \mathrm{wt} \% \mathrm{Cu}$ alloy at different vertical positions $(5,10,15,20,35$, $45,60$ and $85 \mathrm{~mm})$.

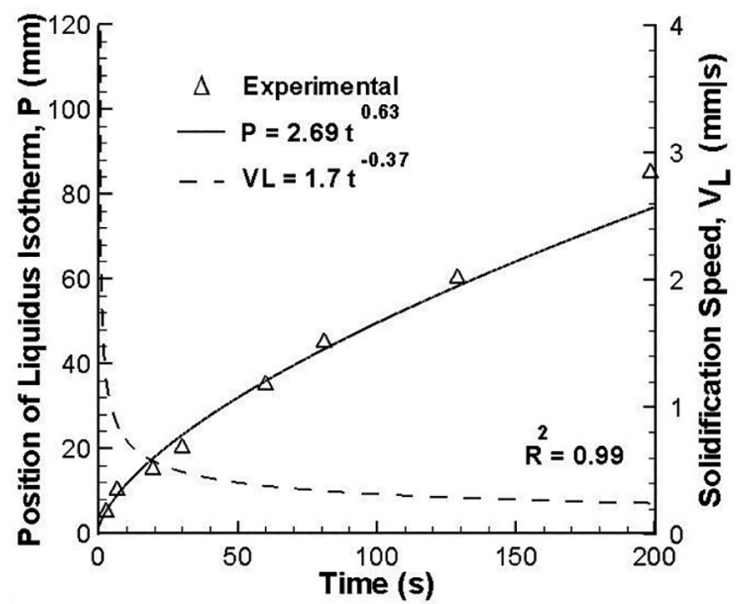

Figure 4. Position of liquidus temperature $(\boldsymbol{P})$ and solidification speed $\left(\boldsymbol{V}_{L}\right)$ versus time. 
The cooling curves were used to found the position of liquidus temperature $(\boldsymbol{P})$ in the solidification process. On the other hand, solidification speed $\left(\boldsymbol{V}_{L}\right)$ used in the present work, were derived from position of liquidus temperature, as shown in Figure 4. In that figure, the solidification speed $\left(\boldsymbol{V}_{L}\right)$ varies significantly with time immediately after the onset of solidification, followed by approximately constant values. From experimental equations $\left(\boldsymbol{P}\right.$ and $\left.\boldsymbol{V}_{L}\right)$ shown in Figure 4, it was possible to obtain an equation for the solidification speed as a function of position, Figure 5 . The mould water-cooling system favors high solidification speed $\left(\boldsymbol{V}_{L}\right)$ at regions close to the cooling bottom. As we move away from mould bottom, the values decreasesas a result of increasing thermal resistance of the solidified material.

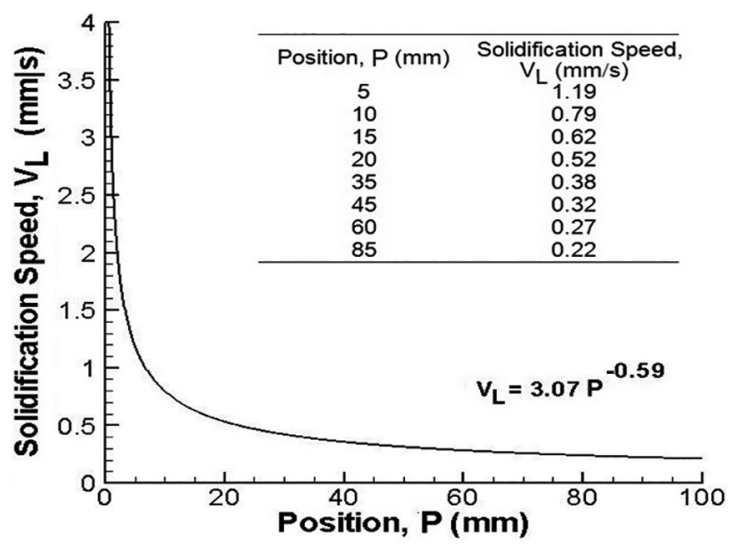

Figure 5. Solidification speed $\left(\boldsymbol{V}_{L}\right)$ versus position $(\boldsymbol{P})$ along the casting length.

Metallographic samples taken from cross sections along the casting are shown in Figure 6. Those samples have been taken perpendicular to the solidification direction and, therefore, show basically the tertiary dendritic arms. In that figure, on the right side of each picture, it is presented information regarding the sample position in the casting $(\boldsymbol{P})$, solidification speed $\left(\boldsymbol{V}_{L}\right)$, cooling rate $(\dot{\boldsymbol{T}})$ and tertiary dendritic arm spacing $\left(\lambda_{3}\right)$. Figure 6 illustrates the effect of thermal variables on the dendritic morphology during the solidification process, through those optical micrographs, one can see that dendritic arm spacing $\left(\lambda_{3}\right)$ decreases dramatically at higher cooling rates $(\dot{\boldsymbol{T}})$. Such an alteration in dendritic arm spacing at higher cooling rates is due to the increasing nucleation rates that lead to a microstructure refinement.

Figure $7 \mathrm{a}-\mathrm{b}$ shows the experimental $\mathrm{Cu}$ and $\mathrm{Si}$ composition profiles measurements. For clarity, the concentration profiles were considered for a range of solid fraction (0 to $60 \%$ ), which is assumed to correspond to the solidification before eutectic and/or any intermetallic phase formation.

Figure 7 (a-b) reveals that both $\mathrm{Cu}$ and $\mathrm{Si}$ concentrations increase gradually as the solidification progresses. It can be seen from Figure 7 (a) that the $\mathrm{Cu}$ profile moves upward with the increase in solidification speed $\left(\boldsymbol{V}_{L}\right)$. This is due to microsegregation phenomenon at the solid/liquid interface, which is usually characterized by the equilibrium partition coefficient $\left(\boldsymbol{K}_{e q}\right)$, which is determined from the phase diagram. The significant deviations between Scheil's equation and experimental data shown in Figure 7 (a), is due to the vertical directional solidification process considered in present work that takes place under non-equilibrium conditions. In contrast to Figure 7 (a), one can see an inverse trend in Si microsegregation (Figure 7 (b)) that is profile of solute concentration moves downward with the increase in solidification speed $\left(\boldsymbol{V}_{L}\right)$. Closer examination of the experimental results shown in Figure $7 \mathrm{a}-\mathrm{b}$, suggests that the Si concentration in the solid phase may have been influenced by multielement interaction in ternary Al-9.0wt $\% \mathrm{Si}-4.0 \mathrm{wt} \% \mathrm{Cu}$ alloy. The growth of $\mathrm{Cu}$-rich dendrites is accompanied by progressive enrichment of residual liquid in $\mathrm{Si}$, i.e., large concentrations of $\mathrm{Cu}$ and correspondingly minute amounts of $\mathrm{Si}$ are recorded in the solid phase for same vertical positions $(\boldsymbol{P})$ of the casting.

In order of improving the prediction capability of Scheil's equation for $\mathrm{Cu}$ concentration, the effective partition coefficient $\left(\boldsymbol{K}_{e f C u}\right)$ is considered in this present work. The eq. (2) has been used to create a plot of $\boldsymbol{K}_{e f \mathrm{Cu}}$ versus $\boldsymbol{V}_{L}$. In order to found a experimental equation of the effective partition coefficient $\left(\boldsymbol{K}_{\text {ef } \mathrm{Cu}}\right)$ as a function of solidification speed $\left(\boldsymbol{V}_{L}\right)$, a curve fitting technique have been used on such points shown in Figure 8.

It is important to emphasize that the experimental equation shown at Figure 8 have been derived for a solidification speed range from 0.22 to $1.19 \mathrm{~mm} / \mathrm{s}$ obtained in the present work, and that for higher solidification rates a tendency to approach $K_{e f C u}=1$ will exist, since Eq. (1) is operative between equilibrium partition coefficient $\left(\boldsymbol{K}_{e q}\right)$ and 1.

Due to the observed inverse trend in Si microsegregation, the Scheil's equation was adjusted preliminary to experimental data (Figure 9) and then the $\boldsymbol{K}_{\text {ef } S i}$ as a function of solidification speed $\left(\boldsymbol{V}_{L}\right)$ can be determined empirically. The Figure 10 shows an empirical equation for effective partition coefficient $\left(\boldsymbol{K}_{e f S i}\right)$ obtained from Scheil's equation adjusted to the experimental data, Figure 9. The solidification speed effect on the $\boldsymbol{K}_{\text {ef } S i}$ can be incorporated for a range of solidification rates between 0.27 and $1.19 \mathrm{~mm} / \mathrm{s}$.

The microsegregation of $\mathrm{Cu}$ and $\mathrm{Si}$ are shown in Figure 11 and 12 , respectively. The profiles ( $\mathrm{Cu}$ and $\mathrm{Si}$ ) were obtained via Scheil's equation using the effective partition coefficients $\left(\boldsymbol{K}_{e f \mathrm{Cu}}\right.$ and $\left.\boldsymbol{K}_{e f \mathrm{Si}}\right)$. The results shown in Figs. 11 and 12 display good agreement between the numerical and experimental data. However, some discrepancies are observed at higher solid fractions $\left(\boldsymbol{F}_{S}>0.4\right)$.

The calculated results underestimate the experimental data for both solutes $\mathrm{Cu}$ and $\mathrm{Si}$ for $\boldsymbol{F}_{S}>0.4$, because the solid back-diffusion was not taken into consideration in the Scheil's equation. In addition to solid back-diffusion, there are other micro-scale phenomena which can affect microsegregation, known as interdiffusion during cooling and coarsening ${ }^{10,11,25}$. 

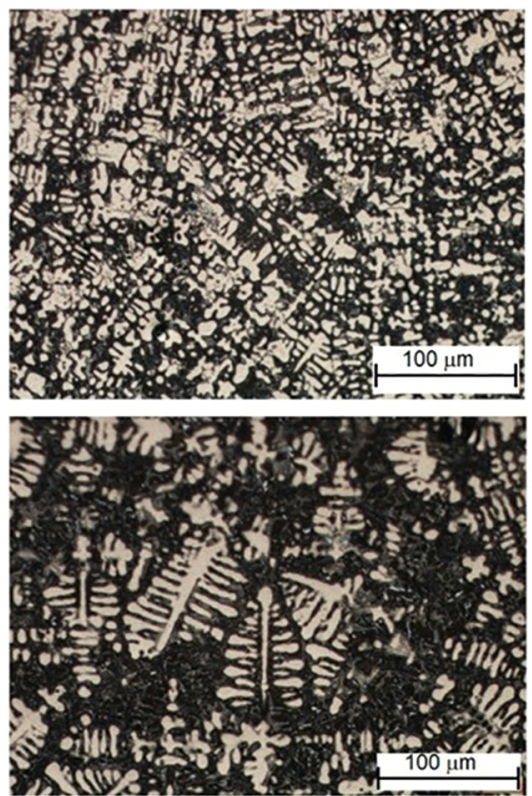

$\boldsymbol{P}=5 \mathrm{~mm}$

$V_{L}=1.19 \mathrm{~mm} / \mathrm{s}$

$\dot{T}=9.03^{\circ} \mathrm{C} / \mathrm{s}$

$\lambda_{3}=20.99 \mu \mathrm{m}$

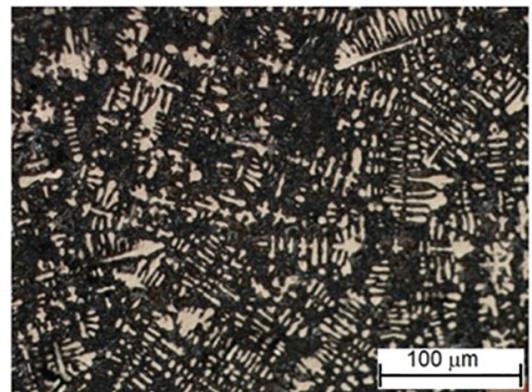

\section{$P=35 \mathrm{~mm}$} $V_{L}=0.38 \mathrm{~mm} / \mathrm{s}$ $\dot{T}=0.82^{\circ} \mathrm{C} / \mathrm{s}$ $\lambda_{3}=29.94 \mu \mathrm{m}$

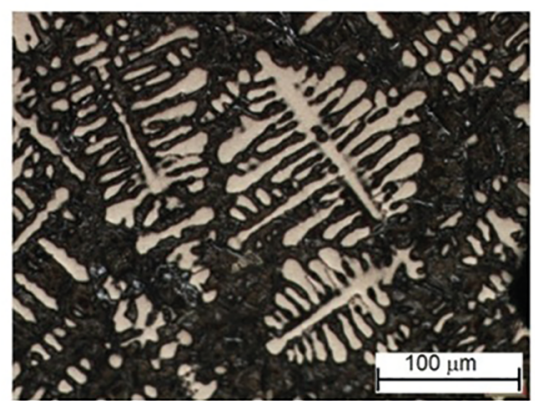

$\boldsymbol{P}=15 \mathrm{~mm}$

$V_{L}=0.62 \mathrm{~mm} / \mathrm{s}$

$\dot{T}=2.34^{\circ} \mathrm{C} / \mathrm{s}$

$\lambda_{3}=22.25 \mu \mathrm{m}$

$P=85 \mathrm{~mm}$

$V_{L}=0.22 \mathrm{~mm} / \mathrm{s}$

$\dot{T}=0.28^{\circ} \mathrm{C} / \mathrm{s}$

$\lambda_{3}=39.98 \mu \mathrm{m}$

Figure 6. Photomicrographs of samples from transverse sections along the casting length.
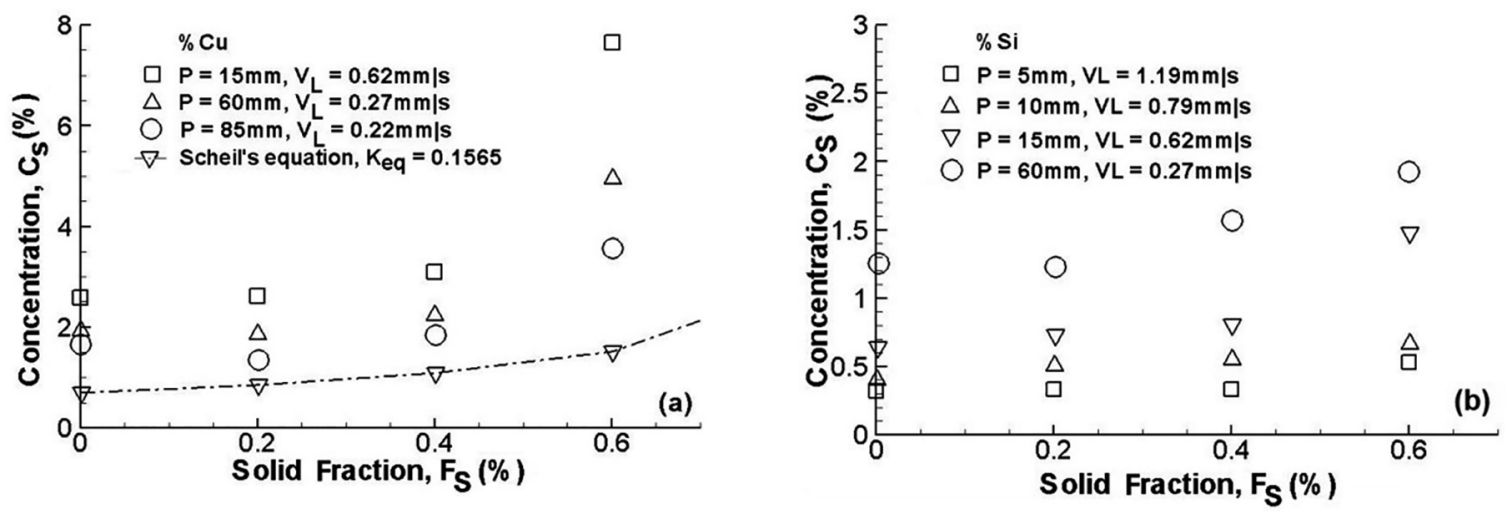

Figure 7. Microsegregation of solutes in the ternary Al-9.0wt $\% \mathrm{Si}-4.0 \mathrm{wt} \% \mathrm{Cu}$ alloy: (a) $\mathrm{Cu}$ and (b) Si.

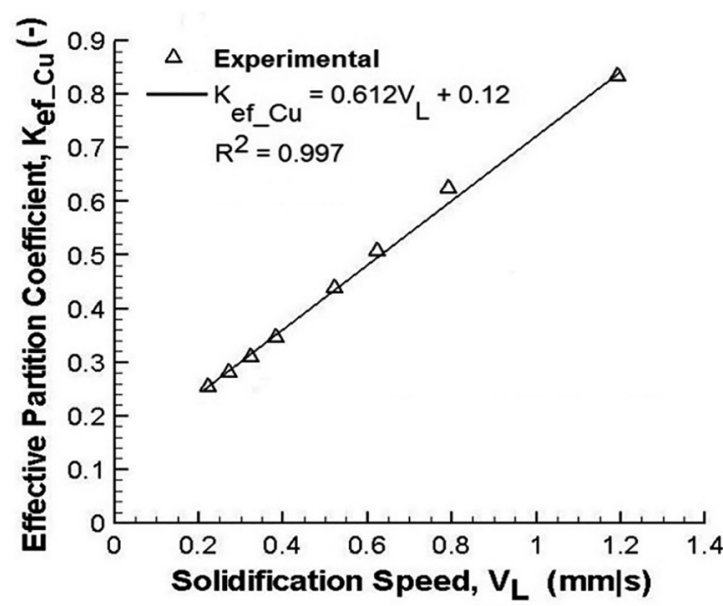

Figure 8. Effective partition coefficient $\left(\boldsymbol{K}_{\text {ef } C u}\right)$ versus solidification speed $\left(\boldsymbol{V}_{L}\right)$.

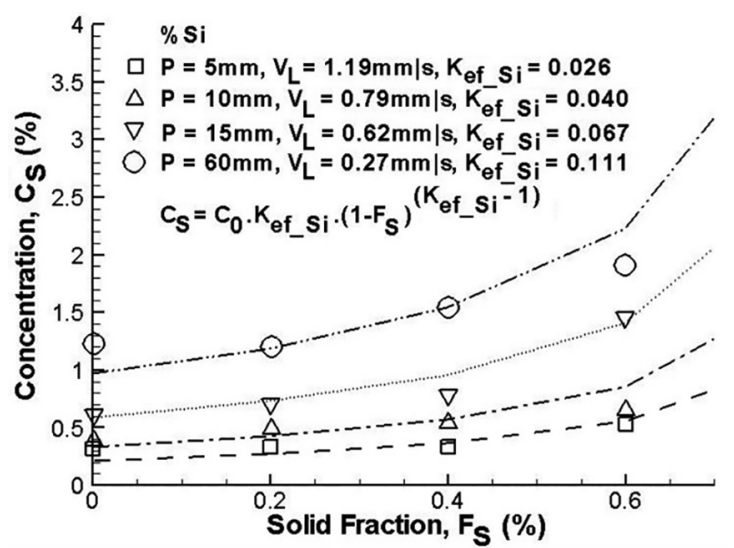

Figure 9. Experimentally measured and calculated microsegregation of the $\mathrm{Si}$ solute in the $\mathrm{Al}-9.0 \mathrm{wt} \% \mathrm{Si}-4.0 \mathrm{wt} \% \mathrm{Cu}$ alloy. 


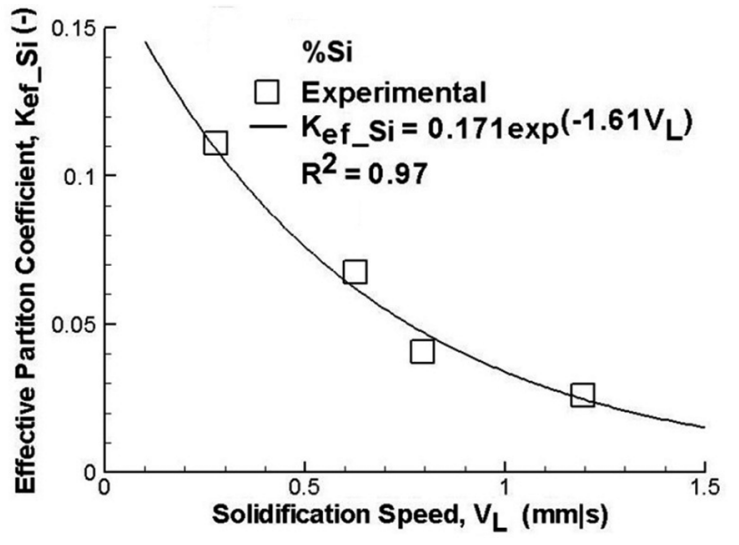

Figure 10. Effective partition coefficient $\left(\boldsymbol{K}_{\text {ef } S_{i}}\right)$ versus solidification speed $\left(\boldsymbol{V}_{L}\right)$.

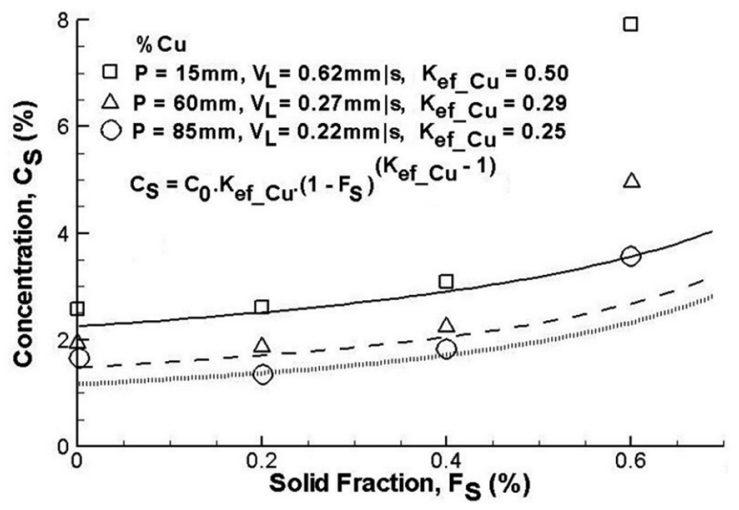

Figure 11. Microsegregation of $C u$ solute in the Al-9.0wt\% $\mathrm{Si}$ $4.0 \mathrm{wt} \% \mathrm{Cu}$ alloy experimentally measured and calculated via Scheil's equation using the effective partition coefficient $\left(\boldsymbol{K}_{\text {ef_Cu }}\right)$.

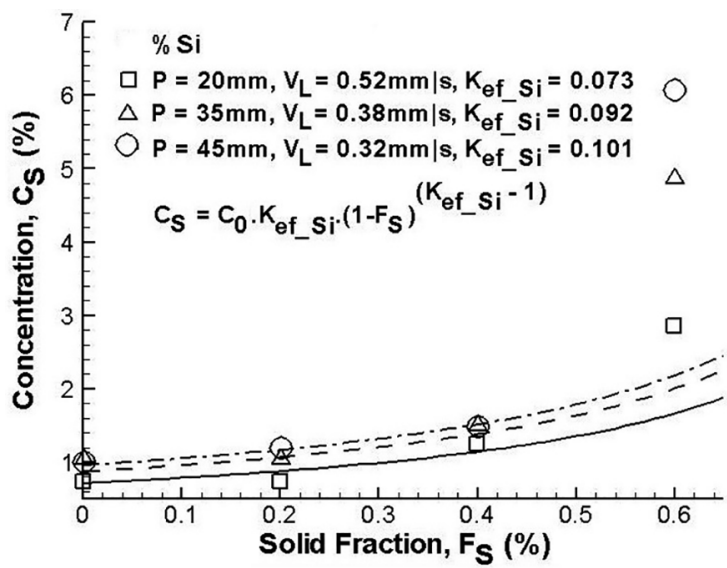

Figure 12. Microsegregation of $\mathrm{Si}$ solute in the ternary Al- $9.0 \mathrm{wt} \% \mathrm{Si}$ $4.0 \mathrm{wt} \% \mathrm{Cu}$ alloy experimentally measured and calculated via Scheil's equation using the effective partition coefficient $\left(\boldsymbol{K}_{\text {ef_Si }}\right)$.

\section{Conclusions}

Solidification speed $\left(\boldsymbol{V}_{L}\right)$ varies significantly with time, immediately after the onset of solidification, followed by approximately constant values. The reason for this is due to increasing thermal resistance of solidified region, in the other words, the increasing of solid region exert a strong influence on the solidification kinetics. Tertiary arm spacing $\left(\lambda_{3}\right)$ decreases with rates $(\dot{\boldsymbol{T}})$, this occurs because there is a increasing of nucleation rate that lead to a microstructure refinement. The results reveal that concentrations of the solutes increase gradually with the solidification progress. These increasing concentrations are due to a solute distribution at the phase interface, which is characterized by the partition coefficient. Theprofile of Si concentration moves downward with increase in solidification speed, this trend suggests that the Si solute in the solid phase have been influenced by multielement interaction effects in ternary $\mathrm{Al}-9.0 \mathrm{wt} \% \mathrm{Si}-$ $4.0 \mathrm{wt} \% \mathrm{Cu}$ alloy. The effect of the solidification speed $\left(\boldsymbol{V}_{L}\right)$ on the microsegregation has been examined by Scheil's equation through the incorporation of $\boldsymbol{V}_{L}$ into an effective partition coefficient $\left(\boldsymbol{K}_{e f}\right)$, which has been determined for the range of solidification speed $\left(\boldsymbol{V}_{L}\right)$ experimentally examined. The effective partition coefficient of $\mathrm{Cu}$ is calculated by Burton's equation, while an experimental equation is proposed for effective partition coefficient of $\mathrm{Si}$, which is based on a best-fit curve to the experimental concentration profiles. The concentrations of solutes $(\mathrm{Cu}$ and $\mathrm{Si})$ calculated by Scheil's equation using effective partition coefficient $\left(\boldsymbol{K}_{\text {ef } \mathrm{Cu}}\right.$ and $\boldsymbol{K}_{\text {ef } S_{i}}$ ) was shown to adjust well to the experimental data. The calculated results via Scheil's equation yielded deviations for a solid fraction above 0.4 , such a deviations is due to solid back-diffusion was not taken into consideration in the said equation.

\section{Acknowledgments}

I would like to express my deep appreciation for the support provided by the Instituto Militar de Engenharia through its Material and Mechanical Engineering Section and PETROBRAS through its Research Center - CENPES, for the use of their Scanning Electron Microscopy and X-ray Microanalyses laboratories that allowed the realization of the present job. My special thanks to the staff of these institutions that have greatly helped in the activities.

\section{References}

1. Salvino IM, Ferreira LO, Ferreira AF. Simulation of Microsegregation in Multicomponent Alloys During Solidification. Steel Research International. 2012;83(8):723-732.

2. Salvino IM, Jácome PAD, Ferreira AF, Ferreira IL. An Analysis of the Physical Properties of Multicomponent Alloy on the Simulation Solidification by Phase-Field Model. Materials Science Forum. 2013;730-732:703-708.

3. Xavier CR, Delgado HG Junior, Castro JA, Ferreira AF. Numerical Predictions for the Thermal History, Microstructure and Hardness Distributions at the HAZ during Welding of Low Alloy Steels. Materials Research. 2016;19(3):520-533. 
4. Ferreira AF, Castro JA, Ferreira LO. Predicting Secondary-Dendrite Arm Spacing of the Al-4.5wt\%Cu Alloy During Unidirectional Solidification. Materials Research. 2017;20(1):68-75.

5. Sun Q, Zhang Y, Cui H, Wang C. Phase field modeling of multiple dendrite growth of Al-Si Binary alloy under isothermal solidification. China Foundry. 2008;5(4):265-267.

6. Wesner E, Chaoudhury A, August A, Berghoff M, Nestler B. A phase-field study of large-scale dendrite fragmentation in Al-Cu. Journal of Crystal Growth. 2012;359:107-121.

7. Trivedi R. Interdendritic Spacing: II. A Comparison of Theory and Experiments. Metallurgical and Materials Transactions A. 1984;15(6):977-982.

8. Kurz W, Fisher JD. Dendrite growth at the limit of stability: tip radius and spacing. Acta Metallurgica. 1981;29(1):11-20.

9. Burton JA, Prim RC, Slichter WP. The Distribution of Solute in Crystals Grown from the Melt. Part I. Theoretical. The Journal of Chemical Physics. 1953;21:1987-1990.

10. Voller VR, Beckermann C. A unified model of microsegregation and coarsening. Metallurgical and Materials Transactions A. 1999;30(8):2183-2189.

11. Voller VR. A semi-analytical model of microsegregation in a binary alloy. Journal of Crystal Growth. 1999;197(1-2):325332 .

12. Spinelli JE, Cheung N, Goulart PR, Quaresma JMV, Garcia A. Design of Mechanical properties of Al-alloys chill castings based on the metal/mold interfacial heat transfer coefficient. International Journal of Thermal Sciences. 2012;51:145-154.

13. Freitas ES, Silva AP, Spinelli JE, Casteletti LC, Garcia A. Inter-relation of Microstructural Features and Dry Sliding Wear Behavior of Monotectic Al-Bi and Al-Pb Alloys. Tribology Letters. 2014;55(1):111-120.

14. Spinelli JE, Ferreira IL, Garcia A. Influence of melt convection on the columnar to equiaxed transition and microstructure of downward unsteady-state directionally solidified sn-pb alloys. Journal of Alloys and Compounds. 2004;384(1-2):217-226.

15. Goulart PR, Cruz KS, Spinelli JE, Ferreira IL, Cheung N, Garcia A. Cellular growth during transient directional solidification of hypoeutectic Al-Fe alloys. Journal of Alloys and Compounds. 2009;470(1-2):589-599.
16. Meza ES, Bertelli F, Goulart PR, Cheung N, Garcia A. The effect of the growth rate on microsegregation: Experimental investigation in hypoeutectic $\mathrm{Al}-\mathrm{Fe}$ and $\mathrm{Al}-\mathrm{Cu}$ alloys directionally solidified. Journal of Alloys and Compounds. 2013;561:193-200.

17. Medrano-Prieto HM, Garay-Reyes CG, Gómez-Esparza CD, Aguilar-Santillán J, Maldonado-Orozco MC, Martínez-Sánchez R. Evolution of Microstructure in Al-Si-Cu System Modified with a Transition Element Addition and its Effect on Hardness. Materials Research. 2016;19(Suppl 1):59-66.

18. Avazkonandeh-Gharavol MH, Haddad-Sabzevar M, Fredriksson H. Effect of partition coefficient on microsegregation during solidification of aluminium alloys. International Journal of Minerals, Metallurgy, and Materials. 2014;21(10):980-989.

19. Gündüz M, Kaya H, Çardili E, Marasli N, Keslioglu K, Saatçi B. Effect of solidification processing parameters on the cellular spacings in the Al-0.1 wt\% Ti and Al-0.5 wt \% Ti alloys. Journal of Alloys and Compounds. 2007;439(1-2):114-127.

20. Chen M, Kattamis TZ. Dendrite coarsening during directional solidification of Al-Cu-Mn alloys. Materials Science and Engineering: A. 1998;247(1-2):239-247.

21. Zhang C, Ma D, Wu KS, Cao HB, Cao GP, Kou S, et al. Microstructure and microsegregation in directionally solidified Mg-4Al alloy. Intermetallics. 2007;15(10):1395-1400.

22. Canté MV, Spinelli JE, Ferreira IL Cheung N, Garcia A. Microstructural Development in Al-Ni Alloys Directionally Solidified under Unsteady-State Conditions. Metallurgical and Materials Transactions A. 2008;39(7):1712-1726.

23. Silva AP, Garcia A, Spinelli JE. Microstructure morphologies during the transient solidification of hypomonotectic and monotectic Al-Pb alloys. Journal of Alloys and Compounds. 2011;509(41):10098-10104.

24. Zheng X, Luo AA, Zhang C, Dong J, Waldo RA. Directional Solidification and Microsegregation in a Magnesium-AluminumCalcium Alloy. Metallurgical and Materials Transactions A. 2012;34(9):3239-3248.

25. Ganesan M, Dye D, Lee PD. A technique for characterizing microsegregation in multicomponent alloys and its application to single-crystal superalloy castings. Metallurgical and Materials Transactions A. 2005;36(8):2191-2204.

26. Chalmers B. Principles of Solidification. New York: John Wiley \& Sons; 1964. 